\title{
Internal hedging of intermittent renewable power generation and optimal portfolio selection
}

\section{Carlo Lucheroni \& Carlo Mari}

Annals of Operations Research

ISSN 0254-5330

Ann Oper Res

DOI 10.1007/s10479-019-03221-2
VOLUME 276/1-2 (2019)

ISSN 0254-5330

Published May 2019

ANNAI FIRST

OPERAT

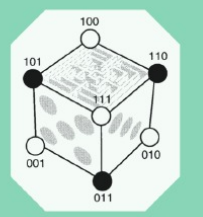

RESEARCH

Editor-in-Chief:

Endre Boros

COMPUTATIONAL BIOMEDICINE

Editors:

Anton Kocheturov, Panos Pardalos,

and George Michailidis

说) Springer

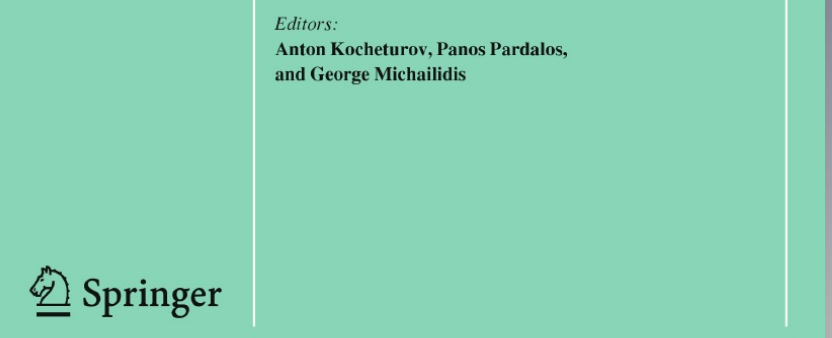

ONLINE

\section{政}

Springer 
Your article is protected by copyright and all rights are held exclusively by Springer Science+Business Media, LLC, part of Springer Nature. This e-offprint is for personal use only and shall not be self-archived in electronic repositories. If you wish to selfarchive your article, please use the accepted manuscript version for posting on your own website. You may further deposit the accepted manuscript version in any repository, provided it is only made publicly available 12 months after official publication or later and provided acknowledgement is given to the original source of publication and a link is inserted to the published article on Springer's website. The link must be accompanied by the following text: "The final publication is available at link.springer.com". 


\title{
Internal hedging of intermittent renewable power generation and optimal portfolio selection
}

\author{
Carlo Lucheroni ${ }^{1}$ (D) $\cdot$ Carlo Mari $^{2}$ \\ (c) Springer Science+Business Media, LLC, part of Springer Nature 2019
}

\begin{abstract}
This paper introduces a scheme for hedging and managing production costs of a risky generation portfolio, initially assumed to be dispatchable, to which intermittent electricity generation from non-dispatchable renewable sources like wind is further added. The proposed hedging mechanism is based on fixing the total production level in advance, then compensating any unpredictable non-dispatchable production with a matching reduction of the dispatchable fossil fuel production. This means making no recourse to short term techniques like financial hedging or storage, in a way fully internal to the portfolio itself. Optimization is obtained in the frame of the stochastic LCOE theory, in which fuel costs and $\mathrm{CO}_{2}$ prices are included as uncertainty sources besides intermittency, and in which long term production cost risk, proxied either by LCOE standard deviation and LCOE CVaR Deviation, is minimized. Closed form solutions for optimal hedging strategies under both risk measures are provided. Main economic consequences are discussed. For example, this scheme can be seen as a method for optimally including intermittent renewable sources in an otherwise dispatchable generation portfolio under a long term capacity expansion perspective. Moreover, within this hedging scheme, (1) production cost risk is reduced and optimized as a consequence of the substitution of the dispatchable fossil fuel generation with non-dispatchable $\mathrm{CO}_{2}$ free generation, and (2) generation costs can be reduced if the intermittent generation can be partially predicted.
\end{abstract}

Keywords Levelized cost of electricity · Renewable energy · Intermittency risk hedging · Risk and deviation measures · Generation portfolios

Carlo Lucheroni

carlo.lucheroni@unicam.it

Carlo Mari

carlo.mari@unich.it

1 School of Science and Technologies, University of Camerino, Via Madonna delle Carceri 9, 62032 Camerino, MC, Italy

2 Department of Economics, University of Chieti - Pescara, Viale Pindaro 42, 65127 Pescara, Italy 


\section{Introduction}

Most contemporary day-ahead electricity markets are based on algorithms that each day match demand and supply for the next day $24 \mathrm{~h}$ (Chen 2017). This arrangement forces electricity producers to compete in prices against each other. Hence, on one hand producers participating to these markets need short term strategies to forecast demand, prices, and the production of other producers in order to maximize their short term profits (Clemens et al. 2016). On the other hand, on longer terms, producers have to take into account capacity planning and expansion, focusing more on costs than on prices, and basing their analysis on construction, fuel, operation and maintenance costs as well (Kagiannas et al. 2004). The Levelized Cost of Electricity (LCOE) is a widespread method suitable for these longer terms and used to take into account the costs that producers bear during the all lifetime of their plants (Madureira 2014). Thus LCOE is used in many official overview studies to compare among each other alternative dispatchable technologies (MIT 2003; IEA-NEA 2015). In fact, different dispatchable technologies can generate the same output of electricity at different costs, so that the same level of revenues can be obtained by different technologies at different costs. More in general, producers often own not only one among many available dispatchable generation technologies, but mixtures of them, i.e. energy portfolios. In this case, LCOE is an even more useful evaluation metric (Lucheroni and Mari 2017). Since different portfolios can produce the same output of electricity, and consequently at the same market prices the same revenues, the portfolio that maximizes the Net Present Value (NPV) is the portfolio that minimizes the LCOE (Lucheroni and Mari 2018a).

Renewable intermittent generation sources like wind have entered into play in recent years, becoming an increasingly consistent part of energy portfolios (Joskow 2011; Reichelstein and Sahoo 2015). This extra uncertainty due to random production of renewable sources has therefore to be assessed and managed both in the short and mid term by energy producers. Yet, in a day-ahead market context in which at a given day a producer must schedule its electricity bids for each hour of the next day, the inclusion of a non-dispatchable source in its portfolio introduces uncertainty about anticipating the very possibility of electricity production. Thus, the inclusion of an intermittent source as wind is not straightforward at all (Hittinger et al. 2010; Roy 2016).

A typical way to handle random production is by injecting it into the power system without restraint and letting the system operator to take care of the reduction or increase in fossil production required to balance production with load. Market penalty systems (European Commission 2010) or financial insurance on committed production in terms of financial derivative contracts are part of this approach. Another possible way to handle random production is the use of storage (Lazard 2015) mainly in the form of hydro pumping or batteries (Hadjipaschalis and Poullikkas 2009) which absorb and release the extra production of a plant at different times.

In this paper we propose a further method to hedge the uncertainty due to random intermittently electricity generation. This method is based on an 'internal' hedging mechanism in which all the non-dispatchable electricity injection into the grid is exactly internally balanced hour by hour in real time by the producer itself (thus not only by the system operator) by reducing the dispatchable component of the energy portfolio of the same electricity amount. This can provide an advantage for the producer, the system operator and the energy system as a whole. Although our scheme can be implemented by choosing any dispatchable energy reducing strategy, we remark that the producer's revenues don't depend on the adopted reducing strategy, whereas different hedging strategies differ from each other in costs. The optimal 
hedging strategy can be therefore determined as that strategy that minimizes the LCOE of the 'hedged' portfolio. On one hand this method allows for a short term, hour by hour hedging of uncertainty of the non-dispatchable component, on the other hand it requires that the costs of this hedging strategy are spread on the long term, i.e. on the whole lifetime of the portfolio. The approach which we propose takes care of the long term by operating at the short term.

We develop this kind of analysis in a general stochastic environment in which in addition to the randomness due to the unpredictability of the intermittent component of the generation portfolio, three further sources of cost risk are taken into account, namely coal and gas (i.e. fossil) fuels prices and $\mathrm{CO}_{2}$ prices (Feng et al. 2011). Cost risk in the electric energy sector is, in fact, mainly due to the high volatility of these risk factors (García-Martos et al. 2013). The evaluation of the cost of the hedging can be made by using the stochastic LCOE method (Lucheroni and Mari 2018a). This technique has the advantage that in this way the hedging risk and cost strategy can be optimized by taking into account both short term and long term aspects of the problem. This optimization is meaningful because different hedging strategies differ from each other in cost and risk, so that producers must face the problem of reducing dispatchable production in an optimal way, by accurately balancing the reductions in the portfolio dispatchable components. Two measures of risk will be used in the paper, namely the standard deviation and the Conditional Value at Risk Deviation (CVaRD) of the stochastic LCOE. The standard deviation is able to capture fluctuations around the mean (Markowitz 1952; Mari 2014; DeLlano-Paz et al. 2017), whereas the CVaRD is a recently introduced risk measure which uses operations research methods to assess asymmetric tail risk by stochastic optimization (Rockafellar and Uryasev 2000; Krokhml et al. 2002; Lucheroni and Mari 2018a). We provide closed form solutions for optimal hedging strategies under both standard deviation and CVaRD risk measures, thus showing that within the proposed hedging scheme, the inclusion of an intermittent source into an otherwise fossil fuels generation portfolio by part of the producer reduces the overall and systemic cost risk in a significant way. This result can be meant as contributing to capacity expansion literature as well, where the capacity expansion can be also optimized in terms of intermittent generation hedging.

For simplicity of exposition, this paper will focus on generation costs of electricity obtained from portfolios composed by just one intermittent renewable source, i.e. wind, and two fossil sources, coal and natural gas, over a thirty years horizon. ${ }^{1}$ The proposed approach can be further extended to include more types of generation sources, both dispatchable and intermittent. In the hedging scheme that we propose, the unpredictable wind electricity produced and injected in the grid is fully compensated at producer's level through the reduction by the same amount of electricity from fossil fuels. On one hand this mechanism generates some extra costs for the producers. The inclusion of a wind farm into an otherwise dispatchable generation portfolio increases the portfolio costs because a wind farm must be constructed and put in operation. On the other hand such an inclusion saves on the total costs of the augmented portfolio because of the electricity reduction from the fossil fuels component of the portfolio when unpredictable wind electricity is generated. We will show that the difference between these extra costs and savings is small in expectation in the case of maximum unpredictability of generation from wind. The wind electricity generating cost, in fact, does not differ too much from variable costs of generating electricity by using fossil fuels technologies such as gas and coal. Moreover, if part of the random intermittency of the wind source can be predicted, it will be shown that its inclusion reduces expected generation costs with respect to case of the fully fossil fuels portfolio. From this point of view, the role of wind generation forecasting can be very relevant in our method. Finally, the addition of an

1 A thirty years horizon is a typical time horizon for LCOE analyses (EIA 2016a). 


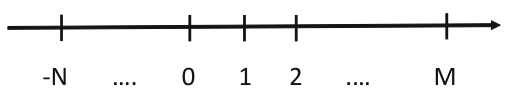

intermittent renewable source, like wind, to a fossil fuels portfolio usually doesn't reduce the fossil fuel component (thus neither $\mathrm{CO}_{2}$ emissions) unless the renewable source replaces part of the fossil based generation. Since in our method the $\mathrm{CO}_{2}$ free source goes to replace fossil fuels usage, the effect of hedging intermittency will be that of reducing fossil fuel, $\mathrm{CO}_{2}$ and overall portfolio risk. A hedged wind farm can be therefore seen as a risk-free asset in an otherwise risky portfolio. In this sense, the contribution of the wind source to the overall risk reduction becomes relevant.

The plan of the paper is the following. After this Introduction, Sect. 2 will discuss the proposed wind hedging scheme mechanism, the behavior of the stochastic LCOE of the hedged portfolio, and a 'modified wind LCOE' definition of the generation portfolio which takes into account the interactions of an intermittent wind source with the dispatchable component of the energy portfolio. This will be a further contribution to current literature on the LCOE of renewable sources. Section 3 will discuss closed form solutions for the optimal hedging strategies, i.e. it will present the solution to the problem of how to find that optimal reduction from each of the fossil contributions to electricity generation which will go to compensate the randomly intermittent wind generation. Section 4 will conclude.

\section{Hedging intermittent renewable power generation}

In this section we present a detailed discussion of our hedging scheme, which intends to optimally integrate non-dispatchable sources in diversified generation portfolios. This section is divided in three subsections. Section 2.1 illustrates some basic results about the stochastic LCOE. Section 2.2 discusses the hedging scheme. In Sect. 2.3 we derive the stochastic LCOE for hedged generation portfolios.

\subsection{Stochastic LCOE: some basic results}

The Levelized Cost of Electricity (LCOE) is defined as that nonnegative price $P^{\mathrm{LC}, x}$ (assumed constant in time, and expressed in real money units) of the electricity produced by a specific generation technology $x$ which makes the present value of expected revenues from electricity sales equal to the present value of all expected costs met during the plant life-cycle (investment costs, operating costs, fuels costs and carbon charges when due). The LCOE is then a breakeven reference unitary cost to be compared with the expected market electricity price.

The stochastic LCOE of an electricity generation technology is the stochastic extension of the deterministic LCOE (Mari 2014). The stochastic LCOE theory is able to include the effect of risk aversion when assessing and managing risk in stochastic breakeven prices (Lucheroni and Mari 2018a).

Consider a project of an electricity generating plant, financially seen as a cash flow stream on a yearly timetable (as depicted in Fig. 1), where $n=-N<0$ is the construction starting time, $n=0$ is the end of construction time and the operations starting time, and $n=M \geq 1$ is the end of operations time. The cash flow evaluation time is $n=0$.

Three sources of risk are taken into account in this study, namely fossil fuels (coal and gas) market prices and $\mathrm{CO}_{2}$ prices. We denote by $\xi$ each possible stochastic sequence of fossil 
fuels and $\mathrm{CO}_{2}$ prices. Since these three sources of risk affect variable costs only, the stochastic LCOE (LC in short) of an electricity generation technology $x$ ( $x=$ ga for gas and $x=$ co for coal) is given by the unitary cost-like real quantity

$$
P^{\mathrm{LC}, x}(\xi)=\tilde{C}^{x, \operatorname{var}}(\xi)+\tilde{C}^{x, \text { fix }}+\frac{\tilde{I}_{0}^{x}-T_{c} d \tilde{e p}^{x}}{\left(1-T_{c}\right)} .
$$

Equation (2.1) is expressed in terms of present values of variable $\operatorname{costs} C_{n}^{x \text {, var }}$ and fixed costs $C_{n}^{x, \text { fix }}$,

$$
\tilde{C}^{x, \operatorname{var}}(\xi)=\frac{\sum_{n=1}^{M} C_{n}^{x, \operatorname{var}}(\xi) F_{0, n}}{\tilde{Q}^{x}}, \quad \tilde{C}^{x, \text { fix }}=\frac{\sum_{n=1}^{M} C_{n}^{x, \mathrm{fix}} F_{0, n}}{\tilde{Q}^{x}},
$$

and construction costs and depreciation,

$$
\tilde{I}_{0}^{x}=\frac{I_{0}^{x}}{\tilde{Q}^{x}}, \quad d \tilde{e p^{x}}=\frac{\sum_{n=1}^{M} d e p_{n}^{x} F_{0, n}}{\tilde{Q}^{x}},
$$

where $T_{c}$, the tax rate. $\tilde{Q}^{x}$ is defined as follows,

$$
\tilde{Q}^{x}=Q^{x} \sum_{n=1}^{M}(1+i)^{n-n_{b}} F_{0, n},
$$

where $Q^{x}$ is the quantity of electricity assumed to be produced in one year, $i$ is the expected inflation rate, and $n_{b}$ is the base year used for computing nominal prices from real prices. $F_{0, n}$ is the discount factor in the WACC evaluation scheme (Ross et al. 2010),

$$
F_{0, n}=\frac{1}{(1+r)^{n}},
$$

where the WACC $r$ is kept constant for the whole life of the project. In Eq. (2.2), the $n$ dependent terms $C_{n}^{x, \text { var }}(\xi)(n \geq 0)$ account for yearly variable costs, namely fuel and $\mathrm{CO}_{2}$ costs, which depend on $\xi$, and operation and maintenance $(\mathrm{O} \& \mathrm{M})$ variable costs. The $n$ dependent terms $C_{n}^{x, \text { fix }}(n \geq 0)$ account for yearly fixed ( $\xi$ independent) costs. In Eq. (2.3), $I_{0}^{x}$ represents lumped pre-operation investment costs, and $d e p_{n}^{x}$ are yearly depreciations. All costs are expressed in nominal terms. Lucheroni and Mari (2018b) provide a detailed derivation of Eq. (2.1). The dynamics of fossil fuels and $\mathrm{CO}_{2}$ market prices is discussed in Mari (2014).

Table 1 details all technical data and costs included in our empirical analysis, for fossil fuels (gas and coal) and wind technologies, denominated in US dollars referred to the base year 2015, i.e. in real dollars. Data shown in Table 1 are collected from the 'Annual Energy Outlook 2016' (EIA 2016b) as reported in 'Capital Cost Estimates for Utility Scale Electricity Generating Plants' (EIA 2016c) provided by the U.S. Energy Information Administration. In accordance to the Annual Energy Outlook 2016 (AEO 2016), we assume an expected inflation rate $i=2.2 \%$ per annum, and a tax rate $T_{c}=40 \%$. Carbon costs have been assumed equal to $25 \$ 2015$ per ton of $\mathrm{CO}_{2}$ (Du and Parsons 2009). As a reference case, we adopt a nominal WACC rate of $7.9 \%$, in agreement with the assumption of a real WACC of $5.6 \%$ adopted in EIA (2016a). LCOE expected values $\mu^{\mathrm{LC}, x}$ can be computed using Eq. (2.1) and data from Table 1. Results are summarized in Table 2.

If we consider a producer owning a portfolio of more than one dispatchable technology, the total stochastic LCOE $P^{\mathrm{LC}, \mathrm{w}}(\xi)$ can be expressed as a linear combination of single technology LCOEs, namely 
Table 1 Technical assumptions

\begin{tabular}{lllll}
\hline & Units & Gas & Coal & Wind \\
\hline Technology symbol & & ga & co & wi \\
Capacity factor $(\%)$ & & 87 & 85 & 42 \\
Heat rate & Btu/kWh & 6600 & 8800 & 0 \\
Overnight cost & $\$ / \mathrm{kW}$ & 956 & 3558 & 1644 \\
Fixed O\&M costs & $\$ / \mathrm{kW} /$ year & 10.76 & 41.19 & 45.98 \\
Variable O\&M costs & mills/kWh & 3.42 & 4.50 & 0 \\
Fuel costs & $\$ / \mathrm{mmBtu}$ & 3.91 & 2.42 & 0 \\
CO 2 intensity & Kg-C/mmBtu & 14.5 & 25.8 & 0 \\
Fuel real escalation rate $(\%)$ & & 2.0 & 0.3 & 0 \\
Construction period & \# of years & 3 & 4 & 3 \\
Plant life & \# of years & 30 & 30 & 30 \\
Operations start & & 2022 & 2022 & 2022 \\
Depreciation scheme & & MACRS,20 & MACRS,20 & MACRS,20 \\
\hline
\end{tabular}

All dollar amounts are in year 2015 dollars. Overnight costs are assumed to be uniformly distributed on the construction period. Mill stands for $1 / 1000$ of a dollar. mmBtu stands for one million Btus. Depreciation is developed according to the MACRS (Modified Accelerated Cost Recovery System) scheme

Table 2 LCOE values (in $\$ 2015$ )

\begin{tabular}{lll}
\hline$\mu^{\mathrm{LC}, \mathrm{ga}}$ & $\mu^{\mathrm{LC}, \mathrm{co}}$ & $\mu^{\mathrm{LC}, \text { wi }}$ \\
\hline 63.8 & 102.5 & 56.8 \\
\hline
\end{tabular}

$$
P^{\mathrm{LC}, \mathrm{w}}(\xi)=\sum_{x} \frac{Q^{x}}{Q} P^{\mathrm{LC}, x}(\xi)=\sum_{x} w^{x} P^{\mathrm{LC}, x}(\xi),
$$

where

$$
Q=\sum_{x} Q^{x}
$$

is the energy produced yearly by the portfolio, and

$$
w^{x}=\frac{Q^{x}}{Q} \quad 0 \leq w^{x} \leq 1,
$$

is the fraction of electricity produced yearly by the technology $x$ in the portfolio, i.e the weight of technology $x$ in the portfolio. The symbol $P^{\mathrm{LC}, \mathrm{w}}(\xi)$ makes explicit the dependency of the LCOE on the portfolio weights. Equation (2.6) follows by considering that the present value of the breakeven costs of a generation portfolio $\tilde{Q} P^{\mathrm{LC}, \mathrm{w}}$ can be expressed as the sum of present values of single technology breakeven costs $\tilde{Q}^{\mathrm{TOT}} P^{\mathrm{LC}, x}$, thus getting

$$
Q P^{\mathrm{LC}, \mathrm{w}}(\xi)=\sum_{x} Q^{x} P^{\mathrm{LC}, x}(\xi)
$$

where tildes disappeared as a direct consequence of Eq. (2.4). 
Table 3 The first four moments of the normalized day-ahead wind power forecasting error distributions (Hodge et al. 2012)

\begin{tabular}{lrlll}
\hline & \multicolumn{1}{l}{ Mean } & SD & \multicolumn{1}{l}{ Skew } & \multicolumn{1}{l}{ Kurt } \\
\hline ERCOT system & 0.0117 & 0.1187 & \multicolumn{1}{l}{-0.616} & 1.0308 \\
Finnish system & -0.0155 & 0.0751 & -0.0720 & 3.1036 \\
Spanish system & 0.0162 & 0.0514 & 0.3855 & 3.0180 \\
Swedish system & -0.0052 & 0.0603 & -0.7252 & 0.7757 \\
Danish system & -0.0005 & 0.0534 & 0.1378 & 2.3859 \\
Irish system & -0.0123 & 0.0827 & 0.3063 & 3.0311 \\
German system & 0.0092 & 0.0450 & -0.2891 & 3.5896 \\
\hline
\end{tabular}

\subsection{The hedging scheme}

The inclusion of an intermittent source such as wind in the LCOE scheme is not straightforward. In a day-ahead market context, in which at a given day a producer must schedule its electricity bids for each hour of the next day, the inclusion of a non-dispatchable source introduces uncertainty in anticipating the very possibility of electricity production for the next day. We propose a model for hedging this kind of risk internally, i.e. without making use of storage technologies (like hydro or batteries) or financial contracts and not relying on the system operator, but by using the dispatchable component of the generating portfolio in order to compensate the unpredictability of intermittent electricity generation. In this way, we will provide optimal electricity generation strategies which minimize the generation cost risk directly at the producer level.

Wind power forecasting is essential to favour greater penetration of wind power into electricity systems. Hourly wind electricity production of the next day can be sometimes partially predicted by numerical weather prediction or statistical analysis of wind data. Several studies address the problem of the day-ahead wind power forecasting (see Jung and Broadwater 2014 for a comprehensive review of the main methods and techniques proposed in the literature). Some of these studies focus on modeling the forecasting error by means of a suitable probability distribution (Lujano-Rojas et al. 2016; Hodge et al. 2012). Some others relay on modeling this error with multivariate GARCH processes (Lucheroni et al. 2019).

Forecasting error distributions can play, in fact, a central role to evaluate the cost of wind integration into well diversified generation portfolios. Hodge et al. (2012) show that forecasting error distributions are leptokurtic with a non zero skewness. Table 3, reconstructed from that paper, reports the first four moments of the normalized day-ahead wind power forecasting error distributions in an international comparison. Hodge et al. (2012) also showed that in some cases, error distributions have a fairly large spread with minimum and maximum error values around half of the installed wind capacity (namely for ERCOT, Finnish and Irish systems). In other cases, forecasting error distributions show a fairly small spread with the largest errors being $<30 \%$ of the installed wind capacity (Swedish, Danish and German systems).

Let us therefore denote by $Q^{\text {wi,pr }}$ the annual amount of predictable wind electricity generation (in case even equal to zero). The total statistically recorded yearly wind production is given by the known value

$$
Q^{\mathrm{wi}} \equiv Q^{\mathrm{wi}, \mathrm{pr}}+Q^{\mathrm{wi}, \text { un }}=8760 \times W^{\mathrm{wi}} \times C F^{\mathrm{wi}},
$$

where $W^{\text {wi }}$ is the nominal wind power capacity (to be included in the dispatchable portfolio) and $C F^{\text {wi }}$ is the operating capacity factor. In fact, although wind generation is highly 
unpredictable on a day ahead basis, the annual amount of the wind unpredictable electricity production $Q^{\text {wi,un }}$ is assumed to be known in advance by statistical means. ${ }^{2}$ Being no recourse to storage or finance allowed in our scheme, the producer should schedule only the electricity he is sure to produce, i.e., in an annual balance,

$$
Q^{\mathrm{TOT}}=\sum_{x} Q^{x}+Q^{\mathrm{wi}, \mathrm{pr}}=Q+Q^{\mathrm{wi}, \mathrm{pr}},
$$

not considering the extra $Q^{\text {wi,un }}$. We denote by $w^{\text {wi }}$ the so-called wind penetration,

$$
w^{\text {wi }}=\frac{Q^{\text {wi }}}{Q},
$$

i.e. the fraction of the wind electricity with respect to the electricity generated by the fossil fuels component of the portfolio. From the knowledge of $Q^{\text {wi,un }}$ and $Q^{\text {wi }}$, we can define a quantity $\gamma$ such that,

$$
Q^{\text {wi,un }}=\gamma Q^{\text {wi }} \quad 0 \leq \gamma \leq 1,
$$

which we will call wind unpredictability parameter. By definition, $\gamma=0$ refers to the fully predictable wind power generation case and $\gamma=1$ refers to the totally unpredictable case.

In this scheme, on each day, and after hourly scheduling, the hourly unpredictable quantity of the electricity generated by the wind above the scheduled quantity is in any case injected into the grid, but at the price of reducing the dispatchable component of the same amount. ${ }^{3}$ Since the electricity generated from gas differs from that generated from coal in cost and risk, producers must thus face the economic problem of reducing dispatchable production in an optimal way in terms of cost and risk, by accurately balancing the reductions in the two dispatchable components.

\subsection{Stochastic LCOE of hedged portfolios}

In order to value costs and risks of different hedging strategies, it must be considered that the inclusion of a wind farm into an otherwise dispatchable generation portfolio has two effects. On one hand it increases the portfolio costs, because the wind farm must be constructed and put in operation. On the other hand, it increases the electricity production of an amount equal

\footnotetext{
2 Annual variability of the intermittent source is not considered in this study. The reason is that the impact it has on the costs of generation portfolios over a thirty years time horizon is negligible, because fluctuations around the average annual electricity production are independent events that cancel each other in average over time. This risk is, in fact, very different from price risks (fossil fuels and $\mathrm{CO}_{2}$ ) which are described by stochastic processes autocorrelated over time, and we can safely avoid to model it.

3 This could seem a penalizing strategy for the producer in those power markets in which all the intermittent renewable energy is injected into the grid on the basis of well defined purchasing agreements, and real time balancing is handled by the system operator. In this case, on the contrary, it is a revenues maximizing strategy too. In fact, if at the $j$ th hour of the $k$ th year a producer generates energy in excess from intermittent sources, say $q_{j, k}^{\text {wi,un }}$, with respect to the scheduled quantity, say $q_{j, k}$, the system operator requires for balancing reasons that some producer reduces its generation of an equivalent quantity $q_{j, k}^{\text {wi,un }}$. The system (i.e. the electricity market) pays the producer for all the injected energy $q_{j, k}+q_{j, k}^{\text {wi,un }}$, and the producer for its service. All in all, only the scheduled amount of electricity $q_{j, k}$ is injected in the power system. In our scheme, the producer injects $q_{j, k}+q_{j, k}^{\text {wi,un }}$, but at the same time signals to the system operator its availability for reducing its generation by $q_{j, k}^{\text {wi,un }}$. In our case the producer enjoys not only the revenue from $q_{j, k}+q_{j, k}^{\text {wi,un }}$ but also the revenue from its dispatching service (for reducing dispatchable production by $q_{j, k}^{\text {wi,un }}$ ).
} 
to $Q^{\text {wi,pr }}$ and reduces the total costs of the augmented portfolio because of the electricity reduction when unpredictable wind electricity is generated. Let us denote by $h Q^{\text {wi,un }}$ and $(1-h) Q^{\text {wi,un }}$ the amounts of gas and coal electricity reduction due to unpredictable wind energy injection into the grid. In the most significant case $\gamma \neq 0$, i.e. when the unpredictable wind electricity $Q^{\text {wi,un }}$ is strictly positive, the unpredictable gas electricity reduction $h Q^{\text {wi,un }}$ cannot be greater than the maximum amount of electricity which can be produced by gas, i.e. $w^{\text {ga }} Q$, as well as the unpredictable coal electricity reduction $(1-h) Q^{\text {wi,un }}$ cannot be greater than the maximum amount of electricity which can be produced by coal, i.e. $w^{\text {co }} Q$. This means that the parameter $h$ must satisfy following constraint

$$
\max \left\{0,1-\frac{w^{\mathrm{co}}}{\gamma w^{\mathrm{wi}}}\right\} \leq h \leq \min \left\{1, \frac{w^{\mathrm{ga}}}{\gamma w^{\mathrm{wi}}}\right\},
$$

which fixes the maximum amount of electricity reduction from each dispatchable source of the starting power portfolio. ${ }^{4}$

Stated in a formal way, the total breakeven cost of the augmented portfolio can be expressed by the following balance equation

$$
\begin{aligned}
Q^{\mathrm{TOT}} P_{h}^{\mathrm{LC}, \mathrm{w}}(\xi)= & \sum_{x} Q^{x} P^{\mathrm{LC}, x}(\xi)+Q^{\mathrm{wi}} P^{\mathrm{LC}, \mathrm{wi}}+ \\
& -h Q^{\mathrm{wi} \text {,un }} \tilde{C}^{\mathrm{ga}, \mathrm{var}}(\xi)-(1-h) Q^{\mathrm{wi} \text {,un }} \tilde{C}^{\mathrm{co,var}}(\xi),
\end{aligned}
$$

where $P^{\mathrm{LC} \text {,wi }}$ is the single technology wind LCOE

$$
P^{\mathrm{LC}, \mathrm{wi}}=\tilde{C}^{\mathrm{wi}, \mathrm{fix}}+\frac{\tilde{I}_{0}^{\mathrm{wi}}-T_{c} \dot{e_{\bar{p}}^{\mathrm{wi}}}}{\left(1-T_{c}\right)},
$$

(for the wind technology variable costs $C^{\text {wi,var }}$ are equal to zero, see Table 1). Under our working hypothesis of three sources of risk, the single-technology wind LCOE $P^{\mathrm{LC} \text {,wi }}$ follows a deterministic price path because the electricity production from a wind source does not burn fossil fuels and does not release $\mathrm{CO}_{2}$. The last two terms in the r.h.s. of Eq. (2.15) account for the variable costs due to the gas and coal electricity generation reduction when unpredictable wind electricity is produced. A specific numerical choice of $h$ thus defines one among many possible global hedging strategies. Consequently, as $h$ varies within the bounds imposed by Eq. (2.14), $P_{h}^{\mathrm{LC}, \mathrm{w}}(\xi)$ defines each possible hedged portfolio stochastic LCOE.

Dividing both members of Eq. (2.15) by $Q^{\mathrm{TOT}}$, it follows that the portfolio LCOE which includes in a hedged way the intermittent power source can be expressed as

$$
\begin{aligned}
P_{h}^{\mathrm{LC}, \mathrm{w}}(\xi)= & \bar{w}^{\mathrm{ga}} P^{\mathrm{LC}, \mathrm{ga}}(\xi)+\bar{w}^{\mathrm{co}} P^{\mathrm{LC}, \mathrm{co}}(\xi)+\bar{w}^{\text {wi }} P^{\mathrm{LC}, \mathrm{wi}}+ \\
& -h \gamma \bar{w}^{\mathrm{wi}} \tilde{C}^{\mathrm{ga}, \mathrm{var}}(\xi)-(1-h) \gamma \bar{w}^{\text {wi }} \tilde{C}^{\mathrm{co}, \mathrm{var}}(\xi),
\end{aligned}
$$

where

$$
\bar{w}^{x}=\frac{w^{x}}{1+(1-\gamma) w^{\mathrm{wi}}},
$$

with $x=$ ga, co and

$$
\bar{w}^{\mathrm{wi}}=\frac{w^{\mathrm{wi}}}{1+(1-\gamma) w^{\mathrm{wi}}} .
$$

4 We assume that the power capacity of fossil fuel components of the starting dispatchable portfolio allows for each electricity reducing admissible strategy described by Eq. (2.14). 
Equation (2.17) can be thus rearranged in the following way

$$
\begin{aligned}
P_{h}^{\mathrm{LC}, \mathrm{w}}(\xi)= & {\left[\bar{w}^{\mathrm{ga}}-h \gamma \bar{w}^{\mathrm{wi}}\right] P^{\mathrm{LC}, \mathrm{ga}}(\xi)+\left[\bar{w}^{\mathrm{co}}-(1-h) \gamma \bar{w}^{\mathrm{wi}}\right] P^{\mathrm{LC}, \mathrm{co}}(\xi) } \\
& +\bar{w}^{\mathrm{wi}} P^{\mathrm{LC}, \mathrm{wi}} \\
& +h \gamma \bar{w}^{\mathrm{wi}}\left[\tilde{C}^{\mathrm{ga}, \mathrm{fix}}+\frac{\tilde{I}_{0}^{\mathrm{ga}}-T_{c} d \tilde{e}^{\mathrm{ga}}}{\left(1-T_{c}\right)}\right] \\
& +(1-h) \gamma \bar{w}^{\mathrm{wi}}\left[\tilde{C}^{\mathrm{co}, \mathrm{fix}}+\frac{\tilde{I}_{0}^{\mathrm{co}}-T_{c} d \tilde{e p^{\mathrm{co}}}}{\left(1-T_{c}\right)}\right],
\end{aligned}
$$

in which Eq. (2.1) has been used. As outlined in the Introduction, revenues generated by differently hedged portfolios are independent on the hedging strategy $h$. As a consequence, the optimal hedging strategy will be determined in a cost-risk optimizing framework, using as a metric the stochastic LCOE expressed by Eq. (2.20).

Finally, we notice that the 'h-hedged' portfolio LCOE can be written as a linear combination of single technology LCOEs, namely

$$
P_{h}^{\mathrm{LC}, \mathrm{w}}(\xi)=w_{h}^{\mathrm{ga}} P^{\mathrm{LC}, \mathrm{ga}}(\xi)+w_{h}^{\mathrm{co}} P^{\mathrm{LC}, \mathrm{co}}(\xi)+w_{h}^{\mathrm{wi}} P_{h}^{\mathrm{LC}, \mathrm{wi}}
$$

with nonnegative weights

$$
w_{h}^{\mathrm{ga}}=\bar{w}^{\mathrm{ga}}-h \gamma \bar{w}^{\mathrm{wi}}, \quad w_{h}^{\mathrm{co}}=\bar{w}^{\mathrm{co}}-(1-h) \gamma \bar{w}^{\mathrm{wi}}, \quad w_{h}^{\mathrm{wi}}=\bar{w}^{\mathrm{wi}},
$$

satisfying the condition

$$
w_{h}^{\mathrm{ga}}+w_{h}^{\mathrm{co}}+w_{h}^{\mathrm{wi}}=1
$$

In Eq. (2.21)

$$
\begin{aligned}
P_{h}^{\mathrm{LC}, \mathrm{wi}}= & P^{\mathrm{LC}, \mathrm{wi}}+h \gamma\left[\tilde{C}^{\mathrm{ga}, \mathrm{fix}}+\frac{\tilde{I}_{0}^{\mathrm{ga}}-T_{c} \tilde{e \tilde{p}} \tilde{\mathrm{ga}}^{\mathrm{ga}}}{\left(1-T_{c}\right)}\right] \\
& +(1-h) \gamma\left[\tilde{C}^{\mathrm{co}, \mathrm{fix}}+\frac{\tilde{I}_{0}^{\mathrm{co}}-T_{c} d \tilde{e p^{\mathrm{co}}}}{\left(1-T_{c}\right)}\right]
\end{aligned}
$$

thus represents a 'modified wind LCOE' definition accounting for the extra costs due to the hedging mechanism. Notice that correctly including intermittency costs in the LCOE is an open issue still currently debated in the literature (Taylor and Tanton 2012; Stacy and Taylor 2015). Thus we hope that Eq. (2.24) can provide a more complete definition of the wind LCOE. In fact, Eq. (2.24) makes also apparent that in our scheme managing intermittent generation originates extra costs beyond $P^{\mathrm{LC} \text {,wi }}$ due to the fact that fixed coal and gas costs must be in any case paid. In the next section we will demonstrate that our method generates extra costs which are small in expectation. The wind electricity generating cost, in fact, does not differ too much from variable costs of generating electricity by using fossil fuels technologies as gas and coal. This feature keeps small these extra costs in the case of maximum unpredictability of generation from wind, i.e. when $\gamma=1$. If part of the random intermittency can be predicted, i.e. if $\gamma<1$, it will thus follow that wind inclusion can reduce expected generation costs with respect to the fully fossil fuels portfolio case.

Notice that $P_{h}^{\mathrm{LC} \text {,wi }}$ depends on the hedging strategy through $h$, but it doesn't depend on $\xi$. A wind farm hedged according to our scheme can be therefore seen as a risk-free asset in an otherwise risky portfolio and it can contribute to risk reduction by diversification in a significant way. Equation (2.21) allows us to quantify the amount of such risk reduction. Namely, only the first two terms in the r.h.s depend on $\xi$ through $P^{\mathrm{LC}, \mathrm{ga}}$ and $P^{\mathrm{LC} \text {,co }}$ with weights $w_{h}^{\mathrm{ga}}$ and $w_{h}^{\mathrm{co}}$. From Eq. (2.23) it follows that $w_{h}^{\mathrm{ga}}+w_{h}^{\mathrm{co}}=1-w_{h}^{\mathrm{wi}}$ thus showing 
that the weight of the wind electricity generation in the augmented portfolio determines the entity of the risk reduction. Since in our hedging scheme the wind generated electricity goes to replace fossil fuels usage, the effect of this kind of hedging intermittency is that of reducing overall portfolio risk through fossil fuels consumption and $\mathrm{CO}_{2}$ emissions reduction. Depending on the value of $w_{h}^{\text {wi }}$ the risk reduction can be very relevant. In the next section we will look for the optimal choice of $h$, in a cost-risk optimizing way.

\section{Optimal hedging}

In this section we provide and discuss closed form solutions for optimal hedging strategies. This section is divided into three subsections. In the first subsection we derive dispatchable generation portfolio frontiers using two measures of risk, namely standard deviation and $\mathrm{CVaRD}$. In the second subsection we discuss optimal hedging strategies for frontier dispatchable portfolios to which a wind component is subsequently added. In the third subsection we discuss optimal hedging strategies for portfolios which already start with minimum cost risk, i.e. a minimum variance or a minimum CVaRD generation portfolio, as that proposed by Lucheroni and Mari (2017), to which a wind component is subsequently added.

\subsection{Dispatchable generation portfolio frontiers}

One of the main implications of the stochastic LCOE theory for fully dispatchable portfolios is that the joint effect of fossil fuel prices volatility and the $\mathrm{CO}_{2}$ price volatility can induce rational electricity producers to diversify their generation portfolios in order to minimize the impact of such factors on the cost risk of electricity production (Lucheroni and Mari 2017). This risk-reducing diversification is not trivial, because the two components of the portfolio, i.e. gas and coal, are coupled through the $\mathrm{CO}_{2}$ price process. In order to discuss this issue we will use a dynamical model in which the time evolution of fossil fuel prices are described by geometric Brownian motions. Fuel prices reported in Table 1 are used as initial conditions of the price dynamics. The numerical values of the dynamical parameters of the model are chosen according to the estimates obtained by Hogue (2012), which used a geometric Brownian motion to fit the fuels prices dynamics on wellhead prices from 19502011 for natural gas, and from 1950-2010 for coal. $\mathrm{CO}_{2}$ prices are assumed to evolve in time according to a geometric Brownian motion (Mari 2014) for which we consider five different volatility scenarios characterized by different values of the volatility parameter $\sigma^{\mathrm{ca}}$, namely $\sigma^{\mathrm{ca}}=0,20 \%, 30 \%, 35 \%, 40 \%$. This assumption tries to depict a zero, medium and a high volatility scenarios in which we can investigate the effects of $\mathrm{CO}_{2}$ price volatility on assessing risk. Empirical LCOE distributions can be obtained by using Monte Carlo techniques. For each run of the Monte Carlo simulation, an evolution path for fossil fuel prices and carbon prices is obtained and, along such paths, LCOE values can be calculated. Table 4 reports the first two moments of the LCOE simulated distribution in each carbon volatility scenario.

By looking at Table 4, it can be seen that the correlation coefficients $\rho$ increases from 0 in the zero-volatility scenario, to 0.67 in the highest volatility scenario. This shows that the coupling between gas and coal stochastic LCOEs strengthens as the carbon price volatility increases. Moreover, the coal LCOE volatility increases more quickly than gas LCOE volatility and, in the last three scenarios, $\sigma^{\mathrm{LC}, \mathrm{co}}$ is larger than $\sigma^{\mathrm{LC}, \mathrm{ga}}$.

Figure 2 depicts dispatchable generation portfolio frontiers in the $\left(-\mu^{\mathrm{LC}, \mathrm{w}}, \sigma^{\mathrm{LC}, \mathrm{w}}\right)$ plane (left panel), and in the $\left(-\mu^{\mathrm{LC}, \mathrm{w}}, \mathrm{CVaRD}^{\mathrm{LC}, \mathrm{w}}\right)$ plane (right panel) for each $\mathrm{CO}_{2}$ price volatility 
Table 4 First two central moments of empirical $P^{\mathrm{L} C, x}(\xi)$ distributions in the five $\mathrm{CO}_{2}$ price volatility scenarios

\begin{tabular}{llrrr}
\hline$\sigma^{c a}$ & $x$ & $\mu^{\mathrm{LC}, x}$ & $\sigma^{\mathrm{L} C, x}$ & $\rho$ \\
\hline 0 & ga & 63.8 & 18.7 & 0 \\
& co & 102.5 & 5.5 & \\
0.20 & ga & 63.8 & 19.7 & 0.24 \\
& co & 102.5 & 13.6 & \\
0.30 & ga & 63.8 & 21.1 & 0.44 \\
& co & 102.5 & 23.5 & 0.54 \\
0.35 & ga & 63.8 & 22.6 & \\
& co & 102.5 & 30.3 & 0.67 \\
0.40 & ga & 63.8 & 25.4 & \\
& co & 102.5 & 40.9 & \\
& & & & \\
\hline
\end{tabular}
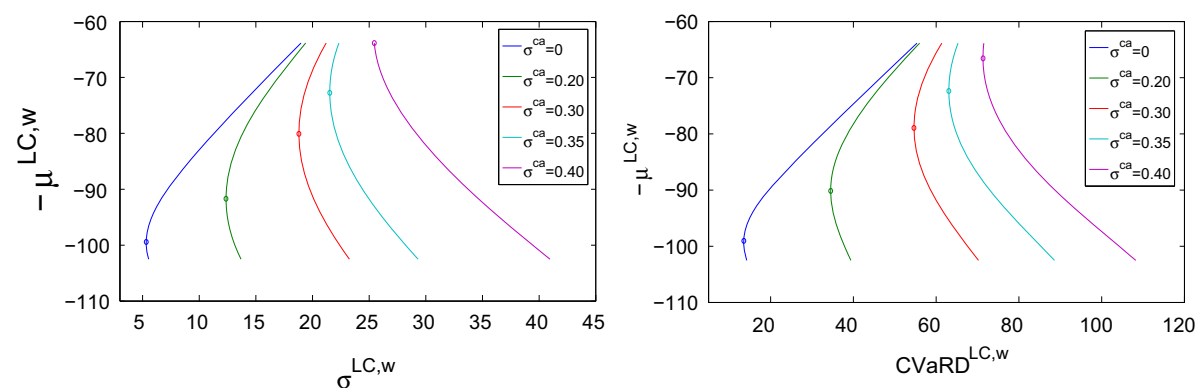

Fig. 2 Dispatchable generation portfolio frontiers for some $\mathrm{CO}_{2}$ price volatility $\left(\sigma^{\mathrm{ca}}\right)$ scenarios. Left panel: The $\left(-\mu^{\mathrm{LC}, \mathrm{w}}, \sigma^{\mathrm{LC}, \mathrm{w}}\right)$ plane. Circles denote minimum variance portfolios. Right panel: The $\left(-\mu^{\mathrm{LC}, \mathrm{w}}, \mathrm{CVaRD}{ }^{\mathrm{LC}, \mathrm{w}}\right)$ plane. Circles denote minimum CVaRD portfolios. On both panels the leftmost curve corresponds to the $\left(\sigma^{\mathrm{ca}}=0\right)$ scenario

Table 5 Composition of dispatchable minimum variance and minimum CVaRD portfolios

\begin{tabular}{llllll}
\hline$\sigma^{\text {ca }}$ & 0 & 0.20 & 0.30 & 0.35 & 0.40 \\
\hline$w_{\text {mvp }}^{\text {ga }}(\%)$ & 8 & 27 & 60 & 80 & 100 \\
$w_{\text {mcp }}^{\text {ga }}(\%)$ & 9 & 31 & 62 & 77 & 93 \\
\hline
\end{tabular}

scenario. ${ }^{5}$ These frontiers are obtained from Eq. (2.6), collecting for each portfolio composition (i.e. for each value of $w^{\text {ga }}$ and of $w^{\text {co }}=1-w^{\text {ga }}$ with $0 \leq w^{\text {ga }} \leq 1$ ) the mean, the standard deviation and the CVaRD of the portfolio stochastic LCOE.

Table 5 reports the composition of minimum variances portfolios (mvp) and minimum CVaRD portolios (mcp) for each $\mathrm{CO}_{2}$ price volatility scenario.

We notice that in each scenario the composition of the mvp-portfolio is very similar to the composition of the mcp-portfolio. This means that a variance-risk averse planner and a tailrisk averse planner would select very similar optimal portfolios. In the first three carbon price volatility scenarios $\left(\sigma^{\mathrm{ca}}=0,0.20,0.30\right)$ the gas component of the mcp-portfolio is greater than the the gas component of the mvp-portfolio. Due to high standard deviation values of the coal LCOE (as reported in Table 4), this relation is reversed in the high carbon volatility scenarios $\left(\sigma^{\mathrm{ca}}=0.35,0.40\right)$. In the highest $\mathrm{CO}_{2}$ price volatility scenario $\left(\sigma^{\mathrm{ca}}=0.40\right)$,

5 For the CVaRD risk measure the confidence level has been taken equal to $95 \%$. 
the coal component of the mvp-portfolio reduces to zero ( $7 \%$ in the mcp-portfolio). As the volatility of carbon prices increases, the coal component as well as the portfolio expected LCOE of such optimal portfolios decrease. This is due to the fact that increasing carbon volatility makes coal generation riskier, thus increasing the gas component and reducing generating cost. In the following Sect. 3.2 we discuss optimal hedging strategies for frontier dispatchable portfolios to which a wind component is added. In turn, in Sect. 3.3 we consider the hedging effect in the case in which the starting portfolio is the minimum variance portfolio or the minimum CVaRD portfolio. In the first case our theory helps to manage at minimum risk the wind component uncertainty, and can be used by producers that want to extend with wind technology a portfolio which was not chosen by taking into account cost risk optimization from scratch. In the second case the optimization can be more effective, since the fossil fuels component of the energy portfolio can be optimized from scratch.

\subsection{Wind inclusion and optimal'h-hedging' strategies}

Equation (2.20) is useful to investigate the mean-risk features of 'h-hedged' portfolios by means of their dependency on $\xi$. In fact, we can compute for each hedging strategy, i.e. for each value of the parameter $h$, the LCOE mean $\mu_{h}^{\mathrm{LC}, \mathrm{w}}$ and standard deviation $\sigma_{h}^{\mathrm{LC}, \mathrm{w}}$ to obtain in the plane $\left(-\mu^{\mathrm{LC}, \mathrm{w}}, \sigma^{\mathrm{LC}, \mathrm{w}}\right)$ the 'h-hedged' portfolios frontier. In a similar way, if we are interested in tail risk, we can use CVaRD as a risk measure and we can compute LCOE mean and CVaRD to obtain in the plane $\left(-\mu^{\mathrm{LC}, \mathrm{w}}, \mathrm{CVaRD}^{\mathrm{LC}, \mathrm{w}}\right)$ the 'h-hedged' portfolios frontier.

The following two main results based on Eq. (2.20) and the underlying dynamic model will be now discussed. First, the inclusion of a wind component as suggested by our method does not modify in a significant way the expected LCOE of the augmented portfolio with respect to the fully dispatchable portfolio. As a consequence, different hedging strategies haven't a relevant impact on the expected LCOE of hedged portfolios. Second, the risk of the hedged portfolio (as measured by standard deviation or CVaRD) depends in a significant way on the adopted dispatchable power reduction strategy.

In order to illustrate the first result (i.e. on mean), we notice that from Eq. (2.17) we can determine the expected LCOE dependence of the hedged portfolio on the hedging strategy, i.e. on the parameter $h$. Namely, taking the expectation of both sides we get

$$
\mu_{h}^{\mathrm{LC}, \mathrm{w}}=\mu_{0}^{\mathrm{LC}, \mathrm{w}}-h \gamma \bar{w}^{\mathrm{wi}} \mathbb{E}\left[\tilde{C}^{\mathrm{ga}, \mathrm{var}}(\xi)-\tilde{C}^{\mathrm{co}, \mathrm{var}}(\xi)\right],
$$

where the symbol $\mathbb{E}$ denotes mathematical expectation mathematical expectation, where $\mu_{0}^{\mathrm{LC}, \mathrm{w}}$ is the h-independent part of Eq. (2.17). The expected LCOE $\mu_{h}^{\mathrm{LC}, \mathrm{w}}$ is a linear function of the hedging parameter $h$ with a slope proportional to the difference between expected variable costs of coal and gas power plants. Such expected costs are independent on the carbon price volatility and, using market data reported in Table 1, they turn out to be 50.0 and $47.8 \$ 2015$ (i.e. dollars referred to our base year 2015) for gas and coal respectively. $\mu_{0}^{\mathrm{LC}, \mathrm{w}}$ is therefore an upper limit for the hedged portfolio expected LCOE. Figure 3 shows the behavior of $\mu_{0}^{\mathrm{LC}, \mathrm{w}}$ as a function of the composition of the starting dispatchable portfolio $w^{\text {ga }}$ for wind penetration values $w^{\text {wi }}=0.2$ and $w^{\text {wi }}=0.4$ (IEA 2016; NREL 2012) in a sequence of three scenarios in $\gamma(\gamma=1,0.6,0.2)$ and for the fully dispatchable portfolio (disp). The values of the parameter $\gamma$ were chosen in agreement with the empirical analysis performed by Hodge et al. (2012) on wind predictability.

In the totally unpredictable case $(\gamma=1)$ the expected LCOE of the 'h-hedged' portfolio is greater than the expected LCOE of the fully dispatchable portfolio (notice the convention on the ordinate axis, in which LCOEs are plotted with a minus sign). Such an increase is 

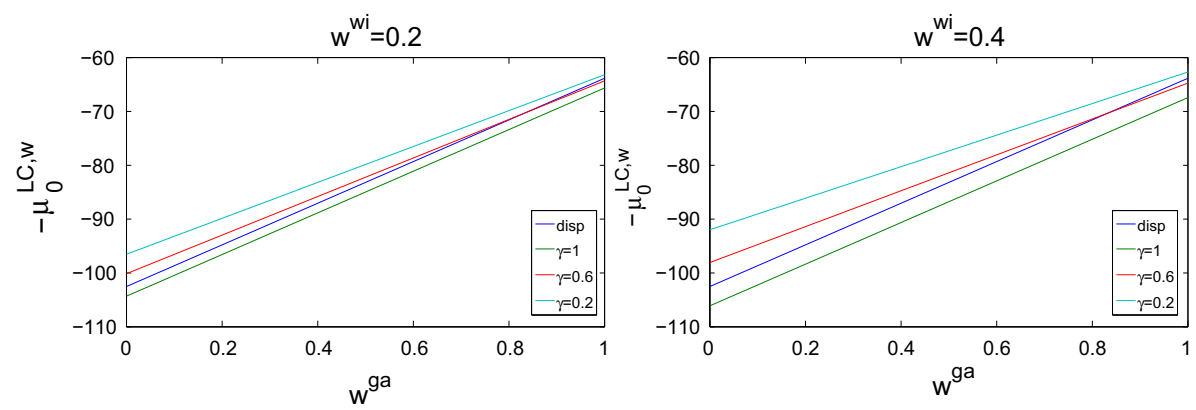

Fig. $3 \mu_{0}^{\mathrm{LC}, \mathrm{w}} v s w^{\mathrm{ga}}$ for a sequence of three scenarios in $\gamma(\gamma=1,0.6,0.2)$ and for the fully dispatchable portfolio (disp). Left panel: The case $w^{\text {wi }}=0.2$. Right panel: The case $w^{\text {wi }}=0.4$. On both panel the lowermost line correspond to $\gamma=1$

less than $1.8 \$_{2015}$ in the case $w^{\text {wi }}=0.2$ and less than $3.6 \$_{2015}$ in the case $w^{\text {wi }}=0.4$ (see the blue line and the green line in Fig. 3). As the unpredictability parameter $\gamma$ decreases, such a difference in cost decreases. For $\gamma=0.6$ (the red line in Fig. 3) the expected LCOE of hedged portfolios is lower than the expected LCOE of the starting dispatchable portfolio for almost all the initial configurations $w^{\mathrm{ga}}$. For $\gamma=0.2$ (the sky blue line in Fig. 3) the expected LCOE of hedged portfolios are always lower than the expected LCOE of the starting dispatchable portfolio. All this means that in cases in which the wind electricity becomes more predictable, the inclusion of a wind component reduces the generation cost (and cost risk, as we will see) with respect to a fully dispatchable portfolio. Remarkably, the sensitivity of the expected LCOE of the hedged portfolio with respect to the parameter $h$ is quite low for each value of $\gamma$. This means that the expected LCOE of the hedged portfolio depends in a very weak way on the dispatchable power reduction strategy. We can use Eq. (3.1) to quantify this sensitivity. Multiplying by $w^{\text {wi }}$ and by $\gamma$ the differences between expected gas and coal variable costs, which is equal to $2.2 \$ 2015$, we get that the maximum contribution (the case $\gamma=1$ ) is less than $0.9 \$_{2015}$ for $w^{\text {wi }}=0.4$.

In order to discuss the second result on risk, we will now show that the risk of the hedged portfolio as measured by standard deviation or CVaRD depends in a significant way on the dispatchable power reduction strategy $h$. Notice that the following analysis can only be made with a stochastic LCOE and not with the usual, deterministic LCOE. This is clearly an advantage of our method. To illustrate such a result, the composition of the dispatchable starting portfolio is chosen as $w^{\mathrm{ga}}=0.5$ and $w^{\mathrm{co}}=1-w^{\mathrm{ga}}=0.5$. From Eq. (2.14) it follows that in such a case $h$ varies from 0 to 1 .

The six panels in Fig. 4 depict 'h-hedged' portfolio frontiers in the LCOE meanstandard deviation $\left(-\mu^{\mathrm{LC}, \mathrm{w}}, \sigma^{\mathrm{LC}, \mathrm{w}}\right)$ plane (left hand side), and in the LCOE mean-CVaRD $\left(-\mu^{\mathrm{LC}, \mathrm{w}}, \mathrm{CVaRD}^{\mathrm{LC}, \mathrm{w}}\right)$ plane (right hand side) as $h$ varies continuously from 0 to 1 for five different carbon price volatility scenarios $\left(\sigma^{c a}=0,0.20 .3,0.35,0.4\right)$ in each panel. The same three different values of the predictability coefficient $\gamma$ as before $(\gamma=1,0.6,0.2)$ are considered. The wind penetration is assumed to be $w^{\text {wi }}=0.4$. Portfolio frontiers rise from the bottom line of the panels with $h=0$ (not-predicted wind in excess is accommodated by reducing the coal component only) to the top of them with $h=1$ (not-predicted wind in excess is accommodated by reducing the gas component only).

We notice that the hedged portfolio risk span (i.e. the difference between maximum and minimum risk values) depends strongly on the hedging strategy in the totally unpredictable 

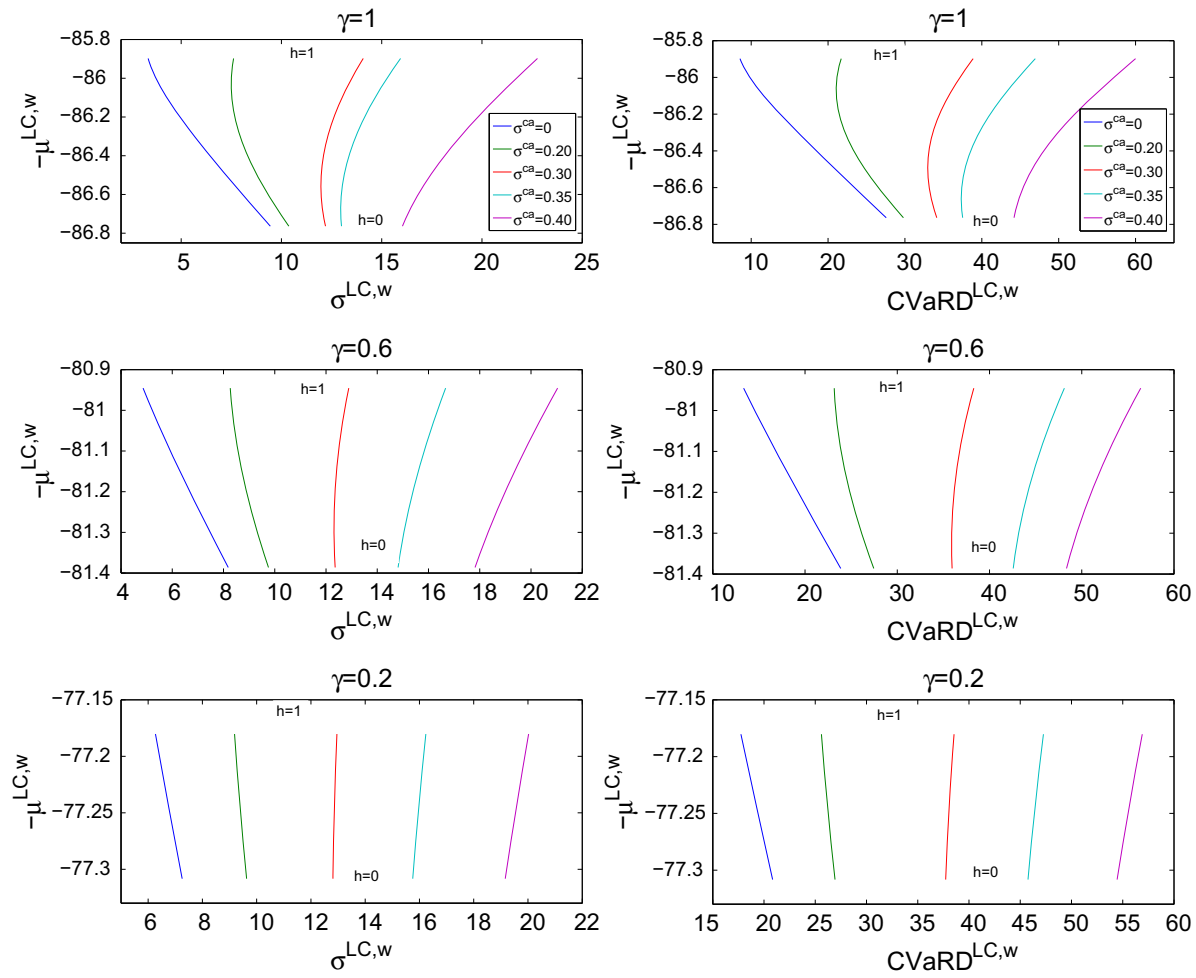

Fig. 4 Hedged portfolio frontiers for the starting dispatchable portfolio with $w^{\text {ga }}=0.5$ and $w^{\text {co }}=0.5$ for three different values of the unpredictability coefficient $\gamma=1,0.6,0.2$. Left hand side: The $\left(-\mu^{\mathrm{LC}, \mathrm{w}}, \sigma^{\mathrm{LC}, \mathrm{w}}\right)$ plane. Right hand side: The $\left(-\mu^{\mathrm{LC}, \mathrm{w}}, \mathrm{CVaRD}^{\mathrm{LC}, \mathrm{w}}\right)$ plane. The wind penetration has been assumed to be $w^{\text {wi }}=0.4$. On all panels the leftmost curve corresponds to $\sigma^{\text {ca }}=0$ scenario

case $(\gamma=1)$, and it decreases as the unpredictability of the wind generation decreases. Moreover, the risk as measured by standard deviation or $\mathrm{CVaRD}$ depends on $\mathrm{CO}_{2}$ price volatility $\sigma^{\mathrm{ca}}$ in crucial way. In fact, the span of standard deviation and CVaRD values assumed by hedged portfolios is quite large for $\sigma^{\mathrm{ca}}=0$. As $\sigma^{\mathrm{ca}}$ increases, the span firstly decreases and then, for large values of $\sigma^{\text {ca }}$, it increases again. This is due to the fact that the gas LCOE standard deviation $\sigma^{\mathrm{LC}, \mathrm{ga}}$ is very large with respect to the coal LCOE standard deviation $\sigma^{\mathrm{LC} \text {,co }}$ (see Table 4). As the $\mathrm{CO}_{2}$ price volatility increases, $\sigma^{\mathrm{LC} \text {,co }}$ increases more quickly with respect to $\sigma^{\mathrm{LC}, \mathrm{ga}}$ thus determining first a reduction of the range of standard deviation and CVaRD values assumed by hedged portfolios, and then, when $\sigma^{\mathrm{LC} \text {,co }}$ is quite larger than $\sigma^{\mathrm{LC} \text {,ga }}$, the range increases again. Moreover, we remark that the impact of optimization is the largest when $\gamma=1$, i.e. in the case of fully wind generation unpredictability. Thus, a producer averse to cost risk, as quantified by variance, would exploit the information contained in these plots by choosing the reduction strategy $h$ in such a way to minimize the fluctuations of the hedged portfolio LCOE around the mean. In this case, the best choice would be a minimum variance hedging strategy. A more sophisticated producer could yet realize that it might be important to stay averse to one side of the distribution only, i.e. to LCOEs larger than the mean. In this second case, an appropriate risk metrics would be still a deviation, but an asymmetric one, like CVaRD. In this case, the best choice would hence 
Table 6 Optimal hedging strategies for the starting dispatchable portfolio with $w^{\mathrm{ga}}=0.5$ and $w^{\mathrm{co}}=0.5$

\begin{tabular}{cccccc}
\hline$\sigma^{c a}$ & 0 & 0.20 & 0.30 & 0.35 & 0.40 \\
\hline$\gamma=1$ & & & & & \\
$h^{\mathrm{mv}}$ & 1 & 0.85 & 0.35 & 0.05 & 0 \\
$h^{\mathrm{mc}}$ & 1 & 0.79 & 0.32 & 0.10 & 0 \\
$\gamma=0.6$ & & & & & \\
$h^{\mathrm{mv}}$ & 1 & 1 & 0.18 & 0 & 0 \\
$h^{\mathrm{mc}}$ & 1 & 1 & 0.12 & 0 & 0 \\
$\gamma=0.2$ & & & & & 0 \\
$h^{\mathrm{mv}}$ & 1 & 1 & 0 & 0 & 0 \\
$h^{\mathrm{mc}}$ & 1 & 1 & 0 & 0 & 0 \\
\hline
\end{tabular}

The wind penetration has been assumed to be $w^{\text {wi }}=0.4 . \sigma^{\text {ca }}$ is the $\mathrm{CO}_{2}$ price volatility and $\gamma$ is the wind unpredictability parameter

be a minimum $\mathrm{CVaRD}$ hedging strategy. For each composition of the dispatchable starting portfolio $w^{\text {ga }}$ and $w^{\mathrm{co}}=1-w^{\mathrm{ga}}$, the optimal hedging strategy, i.e. the minimum variance hedging strategy $h^{\mathrm{mv}}$, or the minimum CVaRD hedging strategy $h^{\mathrm{mc}}$, can be obtained in closed form. To characterize optimal standard deviation and CVaRD hedging strategies, let us pose

$$
\hat{h}^{\mathrm{mv}}=w_{\mathrm{mvp}}^{\mathrm{ga}}+\frac{w^{\mathrm{ga}}-w_{\mathrm{mvp}}^{\mathrm{ga}}}{\gamma w^{\mathrm{wi}}},
$$

and

$$
\hat{h}^{\mathrm{mc}}=w_{\mathrm{mcp}}^{\mathrm{ga}}+\frac{w^{\mathrm{ga}}-w_{\mathrm{mcp}}^{\mathrm{ga}}}{\gamma w^{\mathrm{wi}}} .
$$

The optimal hedging strategies have the following representations:

$$
h^{\mathrm{mv}}= \begin{cases}\hat{h}^{\mathrm{mv}} & \text { if } \max \left\{0,1-\frac{w^{\mathrm{co}}}{\gamma w^{\mathrm{wi}}}\right\} \leq \hat{h}^{\mathrm{mv}} \leq \min \left\{1, \frac{w^{\mathrm{ga}}}{\gamma w^{\mathrm{wi}}}\right\} \\ \min \left\{1, \frac{w^{\mathrm{ga}}}{\gamma w^{\mathrm{wi}}}\right\} & \text { if } \hat{h}^{\mathrm{mv}}>\min \left\{1, \frac{w^{\mathrm{ga}}}{\gamma w^{\mathrm{wi}}}\right\} \\ \max \left\{0,1-\frac{w^{\mathrm{co}}}{\gamma w^{\mathrm{wi}}}\right\} & \text { if } \hat{h}^{\mathrm{mv}}<\max \left\{0,1-\frac{w^{\mathrm{co}}}{\gamma w^{\mathrm{wi}}}\right\},\end{cases}
$$

and

$$
h^{\mathrm{mc}}= \begin{cases}\hat{h}^{\mathrm{mc}} & \text { if } \max \left\{0,1-\frac{w^{\mathrm{co}}}{\gamma w^{\mathrm{wi}}}\right\} \leq \hat{h}^{\mathrm{mc}} \leq \min \left\{1, \frac{w^{\mathrm{ga}}}{\gamma w^{\mathrm{wi}}}\right\} \\ \min \left\{1, \frac{w^{\mathrm{ga}}}{\gamma w^{\mathrm{wi}}}\right\} & \text { if } \hat{h}^{\mathrm{mc}}>\min \left\{1, \frac{w^{\mathrm{ga}}}{\gamma w^{\mathrm{wi}}}\right\} \\ \max \left\{0,1-\frac{w^{\mathrm{co}}}{\gamma w^{\mathrm{wi}}}\right\} & \text { if } \hat{h}^{\mathrm{mc}}<\max \left\{0,1-\frac{w^{\mathrm{co}}}{\gamma w^{\mathrm{wi}}}\right\} .\end{cases}
$$

Appendix A provides a detailed proof of Eqs. (3.4) and (3.5).

Tables 6 and 7 thus report optimal internal hedging strategies, i.e. $h^{\mathrm{mv}}$ and $h^{\mathrm{mc}}$ values, in each considered $\mathrm{CO}_{2}$ price volatility scenario for the starting dispatchable portfolio with $w^{\text {ga }}=0.5$ and $w^{\text {co }}=0.5$ (Table 6 ) and for the starting dispatchable portfolio with $w^{\text {ga }}=0.3$ and $w^{\mathrm{co}}=0.7$ (Table 7).

For the given initial, fully dispatchable portfolios, Tables 6 and 7 can be used as an operating rule for each of the fifteen $\left(\gamma, \sigma^{\text {ca }}\right)$ scenarios. For example, Table 6 shows that in the zero-volatility scenario (first column, $\sigma^{\text {ca }}=0$ ), the optimum hedging strategy consists of a reduction in the gas component only for each value of the unpredictability parameter $\gamma$. As the $\mathrm{CO}_{2}$ price volatility increases (from second to fifth column), the coal component of the 
Table 7 Optimal hedging strategies for the starting dispatchable portfolio with $w^{\mathrm{ga}}=0.3$ and $w^{\mathrm{co}}=0.7$

\begin{tabular}{clllll}
\hline$\sigma^{c a}$ & 0 & 0.20 & 0.30 & 0.35 & 0.40 \\
\hline$\gamma=1$ & & & & & \\
$h^{\mathrm{mv}}$ & 0.63 & 0.35 & 0 & 0 & 0 \\
$h^{\mathrm{mc}}$ & 0.62 & 0.29 & 0 & 0 & 0 \\
$\gamma=0.6$ & & & & & \\
$h^{\mathrm{mv}}$ & 1 & 0.40 & 0 & 0 & 0 \\
$h^{\mathrm{mc}}$ & 0.97 & 0.27 & 0 & 0 & 0 \\
$\gamma=0.2$ & & & & & 0 \\
$h^{\mathrm{mv}}$ & 1 & 0.65 & 0 & 0 & 0 \\
$h^{\mathrm{mc}}$ & 1 & 0.19 & 0 & 0 & 0 \\
\hline
\end{tabular}

The wind penetration has been assumed to be $w^{\text {wi }}=0.4 . \sigma^{\text {ca }}$ is the $\mathrm{CO}_{2}$ price volatility and $\gamma$ is the wind unpredictability parameter

generation portfolio becomes more risky and the hedging strategy of optimal portfolios is a mixed reduction strategy. For the highest value of the carbon price volatility we considered $\left(\sigma^{\mathrm{ca}}=0.40\right)$, the optimum hedging strategy consists in a full reduction of coal power for each value of the $\gamma$ parameter and for both risk measures. In Table 7, a reduction in the coal component only is the optimal strategy also for lower values of $\mathrm{CO}_{2}$ price volatility.

\subsection{Optimal 'h-hedging' strategies for minimum risk dispatchable portfolios}

Let us suppose that the starting dispatchable portfolio is an optimal generation portfolio as, for example a mvp-portfolio or a mcp-portfolio. In such cases, from Eqs. (3.4) and (3.5) it follows that optimal hedging strategies are respectively given by

$$
h^{\mathrm{mv}}=w_{\mathrm{mvp}}^{\mathrm{ga}},
$$

and

$$
h^{\mathrm{mc}}=w_{\mathrm{mcp}}^{\mathrm{ga}} .
$$

i.e. the optimal value of $h^{\mathrm{mv}}$ coincides with the gas component value of the minimum variance portfolio, and the optimal value of $h^{\mathrm{mc}}$ coincides with the gas component value of the minimum CVaRD portfolio. In such optimal cases, the hedging strategy is independent on the unpredictability wind parameter $\gamma$. Figure 5 depicts in the $\left(-\mu^{\mathrm{LC}, \mathrm{w}}, \sigma^{\mathrm{LC}, \mathrm{w}}\right)$ plane (left panel) the hedged portfolios frontier in the case in which the starting portfolio is the mvp dispatchable portfolio, and in the $\left(-\mu^{\mathrm{LC}, \mathrm{w}}, \mathrm{CVaRD}{ }^{\mathrm{LC}, \mathrm{w}}\right)$ plane (right panel) the hedged portfolios frontier in the case in which the starting portfolio is the mcp dispatchable portfolio, for two carbon price volatility scenario, namely $\sigma^{\mathrm{ca}}=0.20,0.30$. In preparing Fig. 5 , the $\mathrm{CO}_{2}$ price volatility scenarios $\sigma^{\mathrm{ca}}=0.20$ and $\sigma^{\mathrm{ca}}=0.30$ were chosen because the corresponding optimal portfolios have large shares of both gas and coal electricity, a condition in which hedging should be more relevant. This notwithstanding, Fig. 5 shows that the risk of hedged portfolios as measured by standard deviation or CVaRD does not vary in a significant way with respect to the adopted hedging strategy. From this point of view, minimum risk gas and coal portfolios play also the important role of mitigating the impact of non-dispatchable sources integration on the overall portfolio risk. 

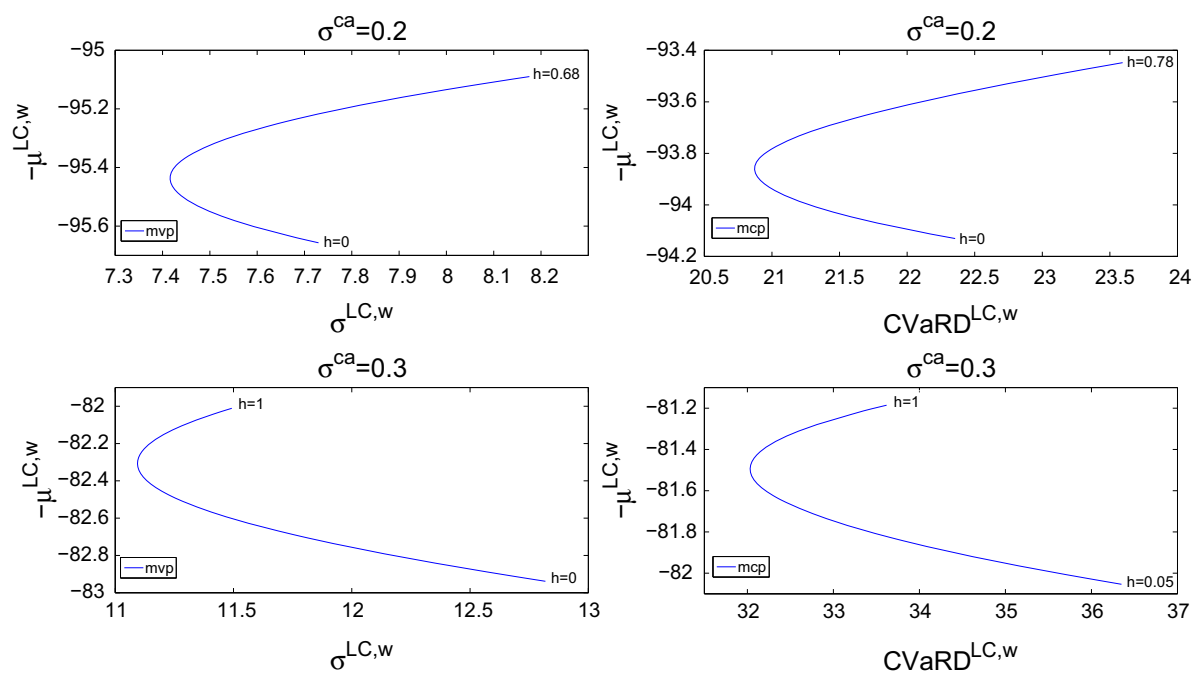

Fig. 5 Hedged portfolio frontiers in the case $\gamma=1$. Left panel: The starting portfolio is the mvp-portfolio. Right panel: The starting portfolio is the mcp-portfolio. The wind penetration has been assumed to be $w^{\text {wi }}=$ 0.4

\section{Concluding remarks}

In this paper we presented a hedging method and an associated risk evaluation/managing scheme useful to include in a controlled way a non-dispatchable renewable electricity generation source in an otherwise dispatchable energy portfolio, for a producer that doesn't want to rely on financial instruments, buffers, or the system operator itself. This method bridges between short term, financial hedging approaches and long term, capacity expansion economic approaches, by providing hedging to intermittency risk on the short run and expansion cost control on the long run. By using the stochastic LCOE approach, in the paper it is demonstrated that once intermittency uncertainty is hedged in the proposed way, the inclusion of the intermittent source reduces the overall portfolio risk, possibly in a consistent way. If in addition the wind production is partly predictable, inclusion of the intermittent source can reduce generation costs as well. The method fixes the hourly electricity production to the level which was bid in the day ahead market, and dynamically reduces the fossil production in such a way that portfolio production keeps itself at that level. This approach, per se interesting for producers, can be interesting even from a broader and policy point of view because, using the proposed hedging scheme, the system operator is alleviated from part of the burden of offsetting intermittent production with dispatchable production, this offset being demanded to a self-interested self-discipline of those producers which own dispatchable plus non-dispatchable plants.

Finally, we remark that the present scheme can be extended in a quite straightforward way to include any bundle of intermittent renewables. If for example we assume that there are $L$ different intermittent generation technologies, labeled by the index $y=1,2, \cdots, L$, the total yearly non-dispatchable ('nd') production is given by

$$
Q^{\mathrm{nd}}=\sum_{y}\left(Q^{y, \mathrm{pr}}+Q^{y, \mathrm{un}}\right)
$$


where $Q^{y, p r}$ and $Q^{y \text {,un }}$ are respectively the predictable component (in case even equal to zero) and the unpredictable component of the electricity generated by the non-dispatchable source $y$. In such a case, the penetration of non-dispatchable sources, i.e. the fraction of electricity generated each year by means of intermittent renewables, is given by

$$
w^{\mathrm{nd}}=\frac{\sum_{y=1}^{L} Q^{y, \mathrm{nd}}}{Q} .
$$

If we pose $Q^{\text {nd,pr }}=\sum_{y} Q^{y, p r}$ and $Q^{\text {nd,un }}=\sum_{y} Q^{y, \text { un }}$, the producer scheduling becomes

$$
Q^{\mathrm{TOT}}=Q+Q^{\mathrm{nd}, \mathrm{pr}} \text {. }
$$

Hence, the LCOE of the non-dispatchable bundle is simply given by

$$
P^{\mathrm{LC}, \mathrm{nd}}=\sum_{y=1}^{L} \frac{Q^{y, \text { nd }}}{Q^{\text {nd }}} P^{\mathrm{LC}, y},
$$

where $P^{\mathrm{LC}, y}$ is the LCOE of the renewable source $y$. Under these positions, the model can be extended to the case of several intermittent sources by replacing the wind quantities labeled by 'wi' with the corresponding non-dispatchable quantities labeled by 'nd'.

\section{A Proof of Eqs. (3.4) and (3.5)}

Let us denote by $D$ a generic deviation measure, like standard deviation or CVaRD. From Eq. (2.20), the cost risk of the hedged portfolio $D\left(P_{h}^{\mathrm{LC}, \mathrm{w}}(\xi)\right)$, can be expressed as ${ }^{6}$

$$
D\left(P_{h}^{\mathrm{LC}, \mathrm{w}}(\xi)\right)=D\left(\left[\bar{w}^{\mathrm{ga}}-h \gamma \bar{w}^{\mathrm{wi}}\right] P^{\mathrm{LC}, \mathrm{ga}}(\xi)+\left[\bar{w}^{\mathrm{co}}-(1-h) \gamma \bar{w}^{\mathrm{wi}}\right] P^{\mathrm{LC}, \mathrm{co}}(\xi)\right) .
$$

Since the coefficients of $P^{\mathrm{LC}, \mathrm{ga}}$ and $P^{\mathrm{LC} \text {,co }}$ do not sum to 1 , we can rearrange Eq. (A.1) in the following way

$$
\begin{aligned}
D\left(P_{h}^{\mathrm{LC}, \mathrm{w}}(\xi)\right)= & \frac{1-\gamma w^{\mathrm{wi}}}{1+(1-\gamma) w^{\mathrm{wi}}} \\
& \times D\left(\left[\frac{w^{\mathrm{ga}}-h \gamma w^{\mathrm{wi}}}{1-\gamma w^{\mathrm{wi}}}\right] P^{\mathrm{LC}, \mathrm{ga}}(\xi)\right. \\
& \left.+\left[\frac{w^{\mathrm{co}}-(1-h) \gamma w^{\mathrm{wi}}}{1-\gamma w^{\mathrm{wi}}}\right] P^{\mathrm{LC}, \mathrm{co}}(\xi)\right),
\end{aligned}
$$

in which Eqs. (2.18) and (2.19) were used. Since the coefficients of $P^{\mathrm{LC}, \mathrm{ga}}$ and $P^{\mathrm{LC}, \mathrm{co}}$ within the $D$ operator sum to 1 , in the case of the standard deviation the minimum risk hedging strategy can now be obtained by solving in $h$ the equation

$$
\frac{w^{\mathrm{ga}}-h \gamma w^{\mathrm{wi}}}{1-\gamma w^{\mathrm{wi}}}=w_{\mathrm{mvp}}^{\mathrm{ga}} .
$$

${ }^{6}$ Let us recall that if $c$ is a constant and $f$ is a random variable, the following relationships hold

$$
\begin{aligned}
D(f+c) & =D(f), \\
D(c f) & =c D(f) .
\end{aligned}
$$


In the case of CVaRD the minimum risk hedging strategy can be instead obtained by solving in $h$ the equation

$$
\frac{w^{\mathrm{ga}}-h \gamma w^{\mathrm{wi}}}{1-\gamma w^{\mathrm{wi}}}=w_{\mathrm{mcp}}^{\mathrm{ga}}
$$

Equations (3.4) and (3.5) follow.

\section{References}

Chen, H. (2017). Power grid operation in a market environment: Economic efficiency and risk mitigation. Wiley-IEEE Press.

Clements, A. E., Hurn, A. S., \& Li, Z. (2016). Strategic bidding and rebidding in electricity markets. Energy Economics, 59, 24-36.

DeLlano-Paz, F., Calvo-Silvosa, A., Iglesias, S., \& Soares, I. (2017). Energy planning and modern portfolio theory: A review. Renewable and Sustainable Energy Reviews, 77, 636-651.

Du, Y., \& Parsons, J. E. (2009). Update on the cost of nuclear power. In MIT working paper.

EIA. (2016). Levelized cost and levelized avoided cost of new generation resources in the annual energy outlook 2016. U.S. Energy Information Administration, Department of Energy.

EIA. (2016). Annual energy outlook 2016. U.S. Energy Information Administration, Department of Energy.

EIA. (2016). Capital cost estimates for utility scale electricity generating plants. U.S. Energy Information Administration, Department of Energy.

European Commission. (2010). Designing appropriate obligations and penalties. Bruxelles, Belgium: Capacity Mechanism Working Group.

Feng, Z. H., Zou, L. L., \& Wei, Y. M. (2011). Carbon price volatility: Evidence from EU ETS. Applied Energy, $88,590-598$.

García-Martos, C., Rodríguez, J., \& Sánchez, M. J. (2013). Modelling and forecasting fossil fuels, $\mathrm{CO}_{2}$ and electricity and their volatilities. Applied Energy, 101, 363-375.

Hadjipaschalis, I., \& Poullikkas, A. (2009). Overview of current and future energy storage technologies for electric power applications. Renewable and Sustainable Energy Reviews, 13, 1513-1522.

Hittinger, E., Whitacre, J. F., \& Apt, J. (2010). Compensating for wind variability using co-located natural gas generation and energy storage. Energy Systems, 1, 417-439.

Hodge, B.-M., et al. (2012). Wind power forecasting error distributions: An international comparison. National Renewable Energy Laboratory.

Hogue, M. T. (2012). A review of the costs of nuclear power generation. BEBR, University of Utah.

IEA. (2016). IEA Wind-2015 annual report. International Energy Agency.

IEA-NEA. (2015). Projected costs of generating electricity. Paris, France: OECD.

Joskow, P. L. (2011). Comparing the costs of intermittent and dispatchable electricity generating technologies. American Economic Review, 101, 238-241.

Jung, J., \& Broadwater, R. P. (2014). Current status and future advances for wind speed and power forecasting. Renewable and Sustainable Energy Reviews, 31, 762-777.

Kagiannas, A. G., Askounis, D. T., \& Psarras, J. (2004). Power generation planning: A survey from monopoly to competition. Electrical Power and Energy Systems, 26, 413-421.

Krokhml, P., Palmquist, J., \& Uryasev, S. (2002). Portfolio optimization with conditional value-at-risk: Objective and constraints. The Journal of Risk, 4, 3-68.

Lazard. (2015). Lazard's levelized cost of storage analysis-version 1.0.

Lucheroni, C., Boland, J., \& Ragno, C. (2019). Scenario generation and probabilistic forecasting analysis of spatio-temporal wind speed series with multivariate autoregressive volatility models. Applied Energy, 239, 1226-1241.

Lucheroni, C., \& Mari, C. (2017). $\mathrm{CO}_{2}$ volatility impact on energy portfolio choice: A fully stochastic LCOE theory analysis. Applied Energy, 190, 278-290.

Lucheroni, C., \& Mari, C. (2018). Risk shaping of optimal electricity portfolios in the stochastic LCOE theory. Computers and Operations Research, 96, 374-385.

Lucheroni, C., \& Mari, C. (2018). Optimal integration of intermittent renewables: A system LCOE stochastic approach. Energies 11.

Lujano-Rojas, J. M., Osório, G. J., Matias, J. C. O., \& Catalão, J. P. S. (2016). Wind power forecasting error distributions and probabilistic load dispatch. Boston: IEEE - Power and Energy Society General Meeting.

Madureira, N. L. (2014). Key concepts in energy. London: Springer.

Mari, C. (2014). Hedging electricity price volatility using nuclear power. Applied Energy, 113, 615-621. 
Markowitz, H. (1952). Porfolio selection. Journal of Finance, 77, 77-91.

MIT. (2003). The future of nuclear power. USA: Cambridge.

NREL. (2012). Renewable electricity futures study. National Renewable Energy Laboratory.

Reichelstein, S., \& Sahoo, A. (2015). Time of day pricing and the levelized cost of intermittent power generation. Energy Economics, 48, 97-108.

Rockafellar, R. T., \& Uryasev, S. (2000). Optimization of conditional value-at-risk. The Journal of Risk, 2 , $21-41$.

Ross, S. A., Westerfield, R. W., \& Jaffe, J. (2010). Corporate finance. NY: McGraw-Hill.

Roy, S. (2016). Uncertainty of optimal generation cost due to integration of renewable energy sources. Energy Systems, 7, 365-389.

Stacy, T. F., \& Taylor, G. (2015). The levelized cost of electricity from existing generation resources. Washington, DC: Institute for Energy Research.

Taylor, G., \& Tanton, T. (2012). The hidden costs of wind electricity. American Tradition Institute.

Publisher's Note Springer Nature remains neutral with regard to jurisdictional claims in published maps and institutional affiliations. 